\title{
QUIZIZZ SEBAGAI MEDIA PEMBELAJARAN UNTUK MELATIH KETERAMPILAN MEMBACA BAHASA JERMAN
}

\author{
Amiroh, Lilis Afifah \\ Universitas Negeri Malang \\ Amiroh.1602416@students.um.ac.id, lilis.afifah.fs@um.ac.id
}

ABSTRAK

ABSTRACT
Keterampilan membaca adalah bagian dari keterampilan berbahasa yang berfokus pada keterampilan seseorang untuk mendapatkan informasi dari sebuah teks. Di dalam pembelajaran bahasa Jerman, keterampilan membaca merupakan hal yang penting untuk dikuasai oleh peserta didik agar mereka dapat memahami makna dari sebuah teks yang sedang dipelajari. Pada kenyataanya, tidak sedikit peserta didik yang merasa jenuh ketika mereka bekerja dengan teks. Oleh karena itu, perlu adanya media pembelajaran yang mampu membangkitkan minat peserta didik untuk melatih keterampilan membacanya. Quizizz adalah media digital yang dapat diaplikasikan dalam pembelajaran karena memiliki tampilan dan fitur yang menarik seperti fitur leadorboard yang akan menampilkan peringkat peserta didik sesuai dengan kecepatan dan ketepatan menjawab soal. Quizizz juga dapat digunakan sesuai dengan kebutuhan pengguna. Berdasarkan uraian tersebut, artikel ini bertujuan untuk membahas konsep media Quizizz sebagai media pendukung untuk melatih keterampilan membaca bahasa Jerman.

Kata Kunci: Keterampilan membaca, bahasa Jerman, Quizizz, media pembelajaran

Reading skills is part of language skilss that focus on one's skill to get information from a text. In learning German, reading skill is important to mastered in order to know the meaning of a text. In fact, some students feel bored when they have to work with texts. Therefore, learning media is needed to increase students interest to practice their reading skill. Quizizz media is digital media that can be applied in learning because it has an attractive apprearance and features such as leaderboard features that will display students rankings according to the speed and accuracy of answering question. Quizizz can also be used according to user requirements. Based on these, this article aims to discuss the concept of Quizizz media as a supporting media for practicing German reading skills.

Keywords: Reading skills, german language, Quizizz, learning media. 
merupakan salah satu bahasa asing yang diajarkan di beberapa sekolah. Iskandarwassid dan Sunendar (2008:89) mengungkapkan bahwa bahasa asing merupakan bahasa yang bukan milik asli dari negara itu sendiri namun penting untuk dipelajari. Sejalan dengan pernyataan tersebut Sobara (2012) menyampaikan bahwa bahasa Jerman merupakan bahasa asing yang diajarkan hampir di seluruh dunia termasuk di Indonesia. Menurut Geothe-Institut (2020), dengan belajar bahasa Jerman seseorang dapat memperoleh kemampuan untuk meningkatkan kualitas hidup profesional seperti, pemahaman kultutral, kesempatan studi dan bekerja di Jerman, serta pemahaman pariwisata dan perhotelan dikarenakan wisatawan dari negara Jerman lebih menyukai pemandu wisata yang dapat berbahasa Jerman.

Bahasa Jerman juga memiliki empat keterampilan berbahasa yang harus dikuasai, salah satunya yaitu keterampilan membaca. Keterampilan membaca merupakan keterampilan yang harus dimiliki setiap peserta didik untuk mengetahui kemampuan peserta didik dalam memahami sebuah teks. Sejalan dengan pernyataan tersebut, Kridalaksana (2011:151) mendeskripsikan bahwa membaca merupakan keterampilan yang sangat mendasar untuk dilakukan oleh peserta didik. Membaca merupakan proses untuk mendapatkan informasi melalui tulisan atau gambar. Iskandarwassid dan Sunendar (2013:246) juga mengutarakan bahwa membaca adalah proses untuk mendapatkan makna yang terdapat dalam tulisan. Menurut Nurgiyantoro (2013:369), tujuan dari membaca adalah untuk mendapatkan informasi serta memperoleh hiburan dan pengetahuan.

Keterampilan membaca bahasa Jerman untuk tingkat SMA juga telah disepakati sesuai dalam aturan yang berlaku pada Gemeinsamer Europäischer Referenzrahmen (GER). Glaboniat (dalam Edrová, 2015:25) mengungkapan bahwa GER merupakan sistem yang mendeskripsikan penilaian keterampilan berbahasa berdasarkan pada kriteria yang telah disepakati. Salah satu tujuan dari pembelajaran bahasa Jerman pada keterampilan membaca bahasa Jerman adalah agar peserta didik dapat memiliki kemampuan membaca bahasa Jerman sesuai dengan standart GER. Standar GER yang dimaksud dalam keterampilan membaca untuk level A1 adalah peserta didik dapat memahami kata-kata dan kalimat yang sederhana terkait keluarga dan lingkungan sekitar.

Berdasarkan uraian di atas dapat disimpulkan bahwa keterampilan membaca merupakan keterampilan yang digunakan untuk mendapatkan makna dan informasi dari sebuah teks. Peserta didik diharapkan dapat memiliki keterampilan membaca bahasa Jerman sesuai dengan standart Gemeinsame Europäische Referenzrahmen (GER).

Pada era saat ini media pembelajaran telah banyak memberikan kemudahan kepada pendidik untuk mencapai tujuan pembelajaran. Sejalan dengan pernyataan tersebut Nurrita (2018) mendefinisikan bahwa media pembelajaran adalah alat yang dapat membantu proses belajar sehingga tercapai tujuan. Munadi (2010:7) juga menjelaskan bahwa media pembelajaran adalah segala sesuatu yang dapat digunakan untuk menyampaikan pesan dari sumber sehingga dapat terjadi proses belajar yang efisien dan efektif. Selain itu, Asyar (2012:8) mengemukakan bahwa media pembelajaran adalah alat yang digunakan 
untuk menyampaikan pesan sehingga lebih mudah tercipta suasana belajar yang lebih kondusif. Seiring berkembangnya zaman media pembelajaran telah mengalami perkembangan yang cukup pesat. Berawal dari media konvensional hingga kini telah berkembang menjadi media digital yang tentu saja lebih memberikan kemudahan. Salah satunya yaitu media Quizizz.

Quizizz merupakan media pembelajaran berbasis digital dalam yang di dalamnya pengguna dapat membuat kuis sesuai yang diinginkan. Media ini adalah media yang sangat mudah digunakan dan dapat digunakan di mana saja. Peserta didik dapat menjalankan Quizizz tidak hanya melalui laptop namun dapat mengunduh aplikasi Quizizz melalui playstore atau appstore atau peserta didik juga dapat mengakses Quizizz melalui web www.quizizz.com dan memasukkan kode kuis untuk masuk pada kuis yang sudah disiapkan oleh pendidik. Kemudian peserta didik dapat menjawab setiap pertanyaan yang sudah disediakan dan dapat melihat skor yang tertinggi pada $L C D$ proyektor apabila peserta didik mengerjakan kuis tersebut di dalam kelas. Quizizz adalah media dengan tampilan yang menarik serta dilengkapi berbagai pilihan tipe soal dengan durasi yang dapat diatur oleh penyusun kuis.

Di dalam sebuah pembelajaran, peserta didik diharapkan dapat memahami materi pembelajaran dengan baik, meskipun tidak jarang juga terdapat peserta didik yang merasa kesulitan dan jenuh pada saat pembelajaran berlangsung. Pendidik dapat menggunakan Quizizz sebagai media pembelajaran untuk memberikan suasana baru bagi peserta didik. Hal ini dapat dibuktikan berdasarkan penelitian terdahulu yang menerapkan media Quizizz sebagai media pembelajaran bahasa Jerman, yaitu penelitian yang dilakukan oleh Hana (2019) dengan judul "Penerapan Media Pembelajaran Quizizz untuk Melatih Kemampuan Gramatika Mahasiswa Jurusan Sastra Jerman Universitas Negeri Malang”. Hasil yang didapatkan dari penelitian tersebut adalah media ini dapat meningkatkan semangat belajar peserta didik. Hasil dari penelitian tersebut menyatakan bahwa kelebihan yang terdapat pada sistem ranking memberikan suasana yang baru serta fitur hitung mundur yang terdapat pada Quizizz dinilai dapat memberikan motivasi dalam belajar, meskipun di lain pihak sistem tersebut memberikan tekanan bagi peserta didik.

Berdasarkan pengalaman penulis ketika melaksanakan Kajian Praktik Lapangan (KPL) di SMAN 9 Malang pada Juli hingga September 2019, didapatkan informasi bahwa bahasa Jerman merupakan bahasa yang cukup sulit untuk dipahami oleh peserta didik. Hal ini diperkuat dengan pernyataan dari guru bahasa Jerman di sekolah tersebut yang mengatakan bahwa hanya 10\% peserta didik yang memahami bahasa Jerman, karena sebagian besar dari mereka cenderung tidak memperhatikan penjelasan pendidik ketika pembelajaran berlangsung. Ketika media digital diterapkan di dalam kelas, peserta didik menjadi lebih bersemangat untuk mempelajari bahasa Jerman dengan melewati kuis-kuis sederhana. Berangkat dari situasi tersebut, artikel ini bertujuan untuk memberikan alternatif media pembelajaran dalam melatih keterampilan membaca bahasa Jerman. pembelajaran digital untuk melatih keterampilan membaca bahasa 
Jerman. Metode yang dipakai adalah dengan menggabungkan pemikiran yang ada dengan teori yang relevan.

PEMBAHASAN
Pada media Quizizz soal disajikan dalam berbagai bentuk seperti multiple choice dimana peserta didik diharuskan menjawab soal dengan empat pilihan ganda atau lebih. Selain itu juga terdapat checkbox, peserta didik dapat menjawab soal seperti pada tipe multiple choice namun dalam bentuk yang berbeda yaitu dengan mengklik tanda centang $(\sqrt{ })$ pada jawaban yang benar. Bentuk soal lainnya adalah fillin-the-blank, pada tipe ini peserta didik akan mengetik secara langsung jawaban yang dianggap benar pada kotak yang tersedia. Kemudian pada soal dengan bentuk poll, jawaban yang mendapat polling tertinggi akan dijadikan sebagai jawaban yang benar. Bentuk yang terakhir adalah open ended, pada tipe soal ini peserta didik dapat menjawab pertanyaan soal dengan bebas tanpa adanya pilihan jawaban.

Pendidik dapat memilih setiap tipe soal yang telah disediakan oleh Quizizz. Di dalam pemilihan soal untuk melatih keterampilan membaca bahasa Jerman penulis memproduksi soal berdasarkan sumber buku yang digunakan yaitu Studio D Al dengan menggunakan KD 3.4 dan 3.5. KD tersebut berfokus pada kemampuan peserta didik untuk menafsirkan teks khusus dan deksriptif. Tema yang penulis pilih adalah Schulleben (kehidupan di sekolah) untuk kelas X sekolah menengah atas. Penulis juga memberikan materi tambahan seperti penggunaan $W$-Frage dan penyebutan jam dalam bahasa Jerman untuk mendukung soal yang akan disajikan. Berikut merupakan langkahlangkah penggunaan Quizizz dan contoh soal yang disajikan pada Quizizz untuk melatih keterampilan membaca bahasa Jerman peserta didik.

Pada tampilan utama Quizizz, peserta didik dapat memasukkan kode soal di kolom "enter game code" atau dengan mengklik "enter code" seperti yang terlihat pada gambar 1 . 


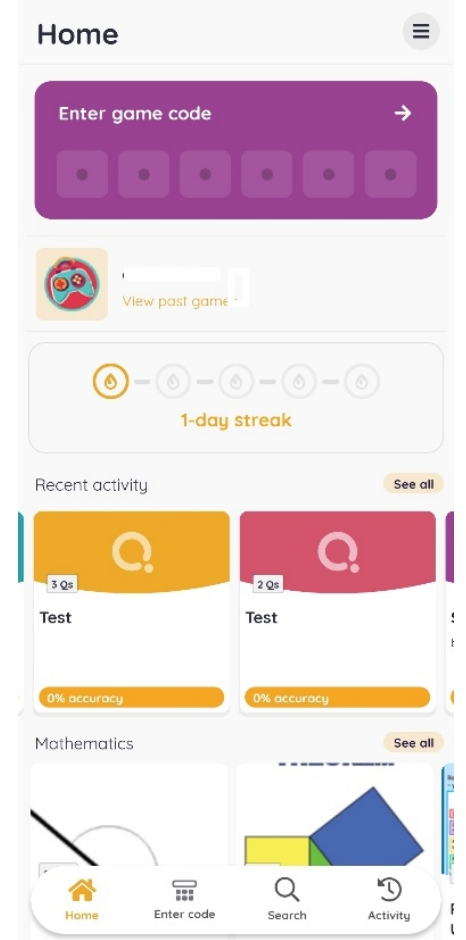

Gambar 1 Tampilan utama Quizizz

Sumber: Aplikasi Quizizz

\section{Q.uIzızz}

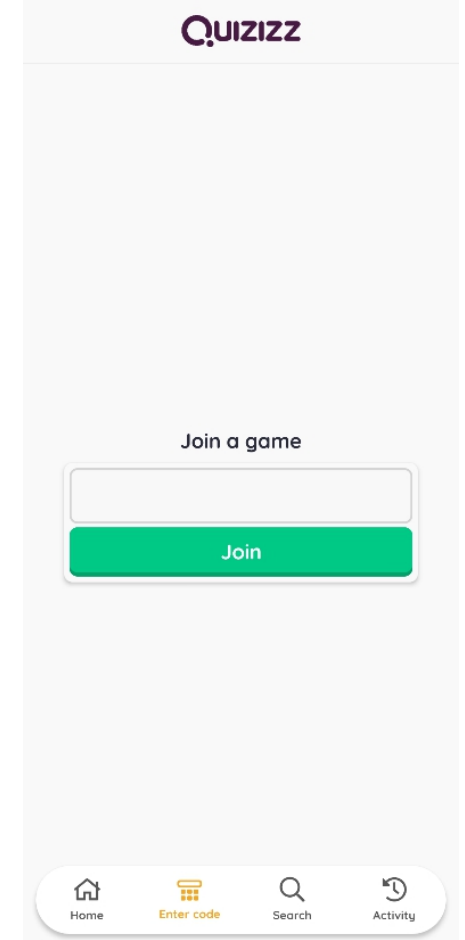

Gambar 2 Tampilan kolom untuk memasukkan kode permainan Sumber: Aplikasi Quizizz

Pada bagian ini peserta didik harus memasukkan kode kuis untuk dapat memulai sebuah kuis. Setelah peserta didik memasukkan kode tersebut maka peserta didik akan diarahkan langsung pada soal kuis seperti yang terdapat pada gambar 3 . 


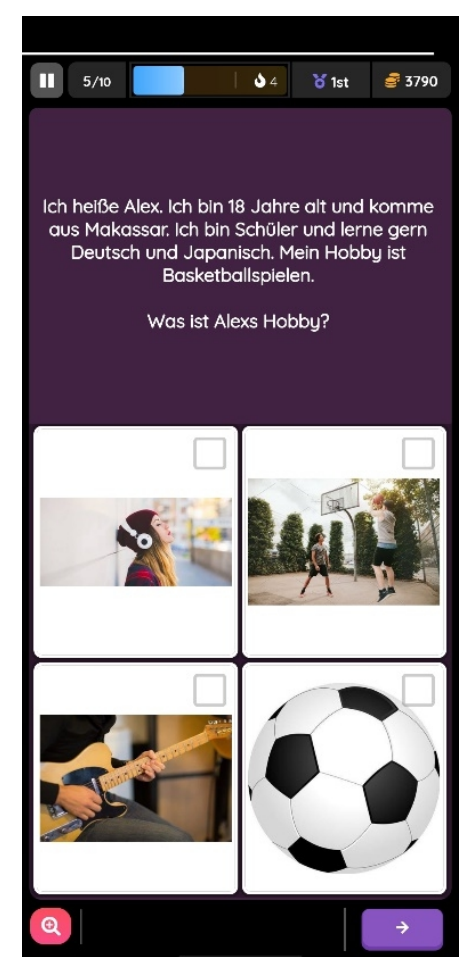

Gambar 3 Tampilan soal dengan tipe Checkbox

Sumber: Aplikasi Quizizz

Peserta didik dapat mulai mengerjakan kuis yang ada dengan jawaban yang benar. Selain bentuk soal Checkbox seperti yang terdapat pada gambar 3, penulis juga menyajikan soal dalam bentuk poll, multiple choice, fill in the blank dan open ended, seperti yang terdapat pada gambar 4, 5, 6 dan 7 .

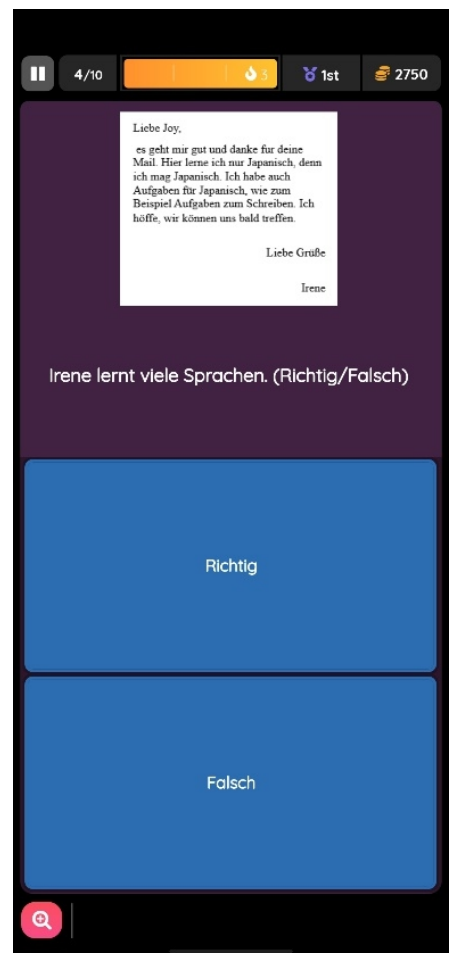

Gambar 4 Tampilan soal dengan tipe Poll

Sumber: Aplikasi Quizizz 


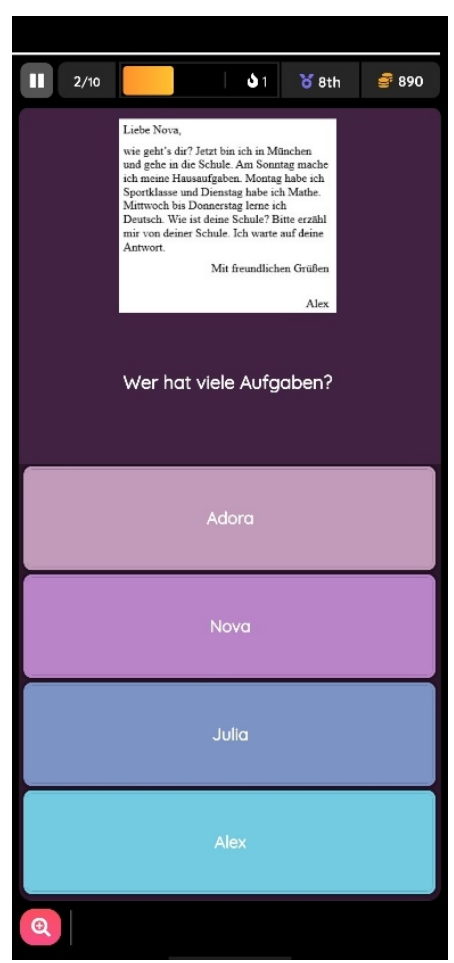

Gambar 5 Tampilan soal dengan tipe Multiple Choice Sumber: Aplikasi Quizizz

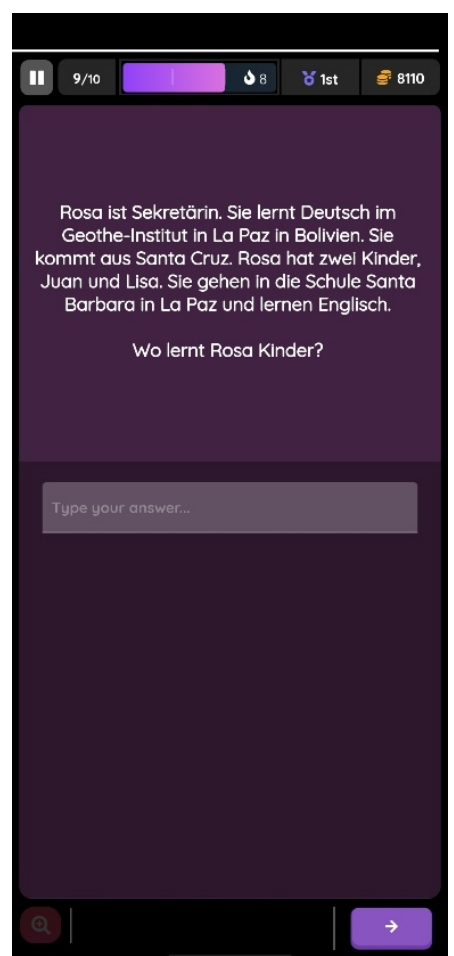

Gambar 6 Tampilan soal dengan tipe Fill in the Blank Sumber: Aplikasi Quizizz 


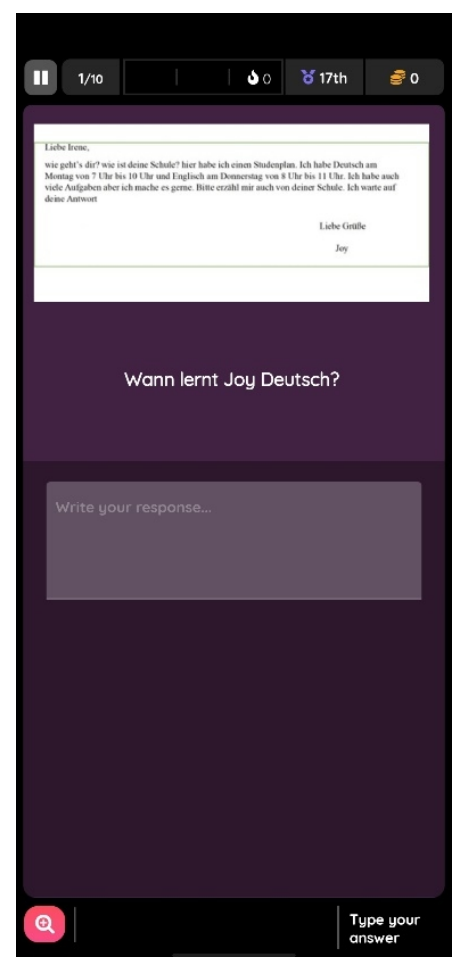

Gambar 7 Tampilan soal dengan tipe Open Ended Sumber: Aplikasi Quizizz

Terdapat salah satu fitur yang menarik pada Quizizz yaitu leaderboard. Ketika peserta didik selesai mengerjakan setiap soal akan muncul tampilan peringkat sesuai dengan kecepatan dan ketepatan menjawab. Fitur ini dapat memberikan semangat lebih pada peserta didik dalam mengerjakan soal. Berikut merupakan tampilan peringkat yang akan muncul selesai mengerjakan soal:

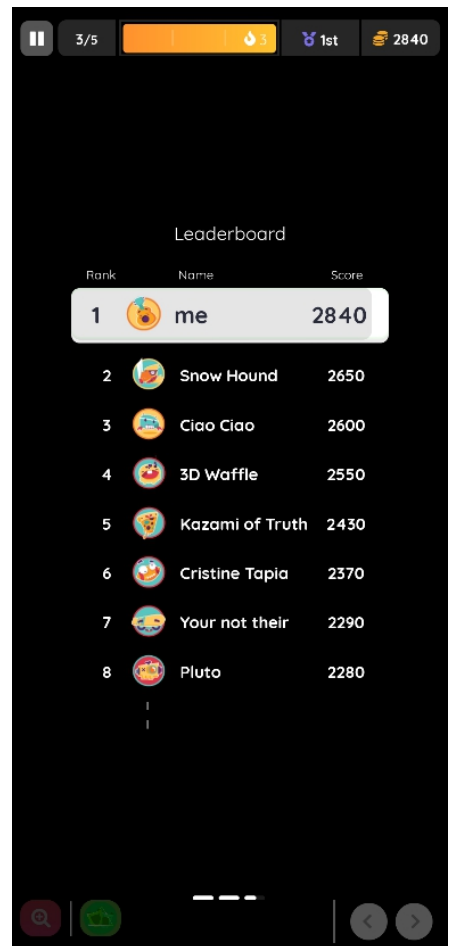

Gambar 8 Tampilan Leaderboard

Sumber: Aplikasi Quizizz 
Setelah peserta didik menyelesaikan semua soal, Quizizz akan menampilkan jumlah soal yang benar dan salah serta waktu yang dihabiskan untuk mengerjakan soal seperti pada tampilan berikut:

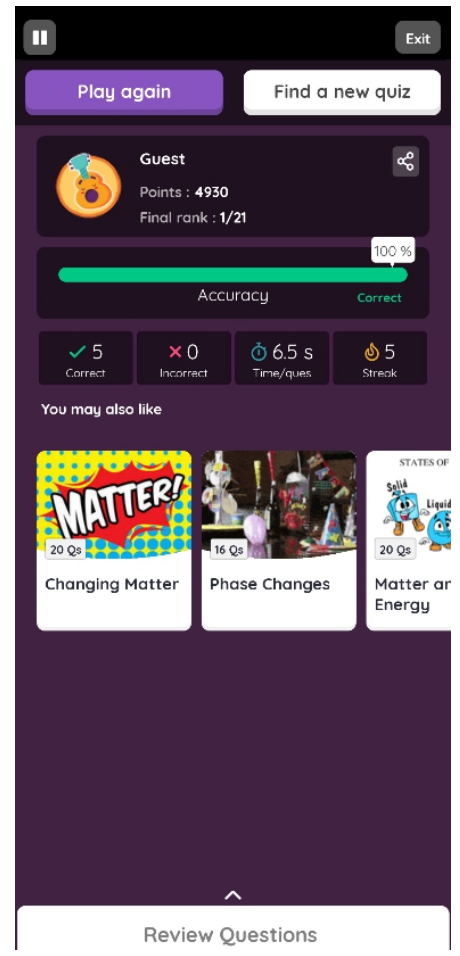

Gambar 9 Tampilan Akhir Kuis

Sumber: Aplikasi Quizizz

Di dalam aplikasi Quizizz juga terdapat fitur durasi pada setiap soalnya. Sehingga hal ini mendorong peserta didik untuk berpikir secara cepat. Durasi yang disajikan juga beragam mulai dari 5 detik hingga 15 menit, yang dapat disesuaikan dengan tingkat kesulitan soal. Berikut merupakan gambar durasi pada soal. 


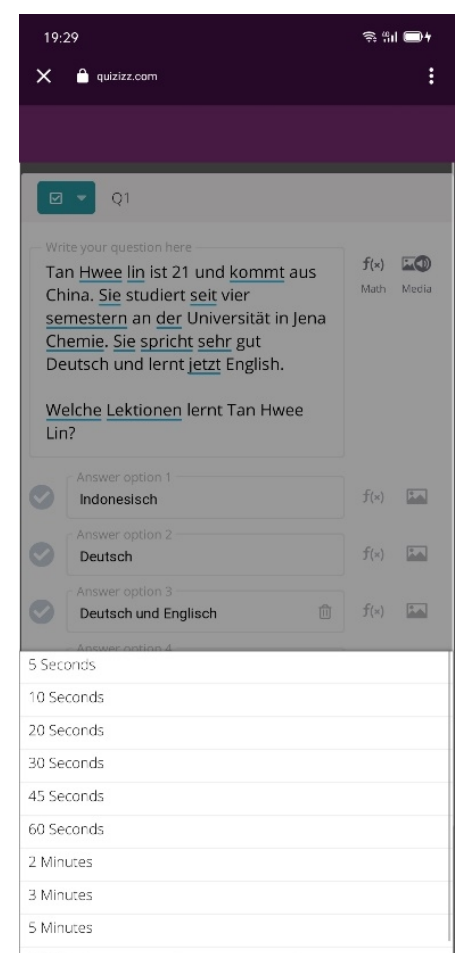

Gambar 10 Tampilan Pilihan Durasi

Sumber: Aplikasi Quizizz

Selain fitur yang telah dijelaskan dibatas, terdapat fitur lain yaitu Review Question. Pada fitur ini pendidik dan peserta didik dapat membahas kembali mengenai soal-soal yang telah selesai dikerjakan. Selain itu, terdapat fitur Redemption Question yang memberikan kesempatan bagi peserta didik untuk memilih salah satu soal dengan jawaban salah agar dapat diperbaiki. Pada fitur ini peserta didik hanya dapat memilih satu soal untuk diperbaiki. Berikut merupakan tampilan dari review Question dan redemption Question.
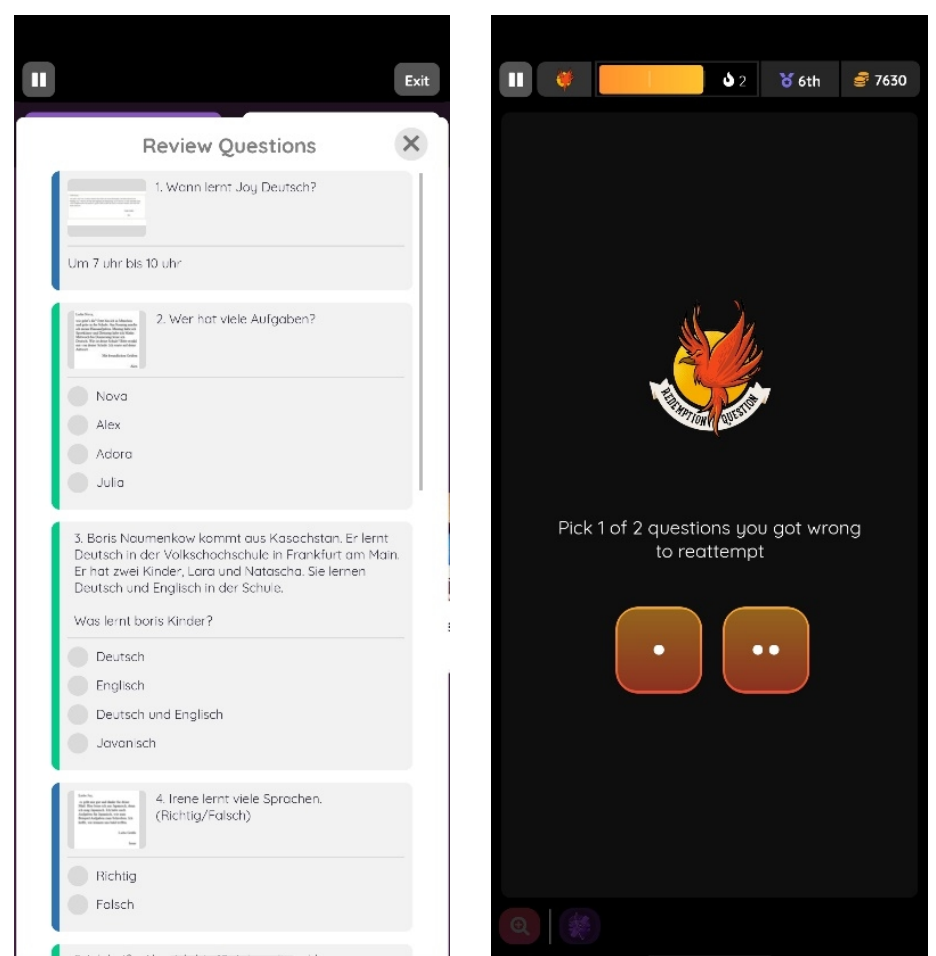

Gambar 11 Tampilan Review Question dan Redemption Question 
Soal Quizizz yang telah penulis susun dapat diakses melalui link berikut: https://quizizz.com/admin/quiz/5ee76a397537ff008b0d6b . Link tersebut dapat diakses tanpa mengunduh aplikasi Quizizz melalui playstore/appstore.

Quizizz merupakan media digital yang dapat digunakan di dalam pembelajaran saat ini. Tampilan yang menarik serta fitur Leaderboard dan durasi yang terdapat di setiap soal akan memberikan suasana dan semangat dalam pembelajaran selain itu, fitur review Question dapat membantu pendidik dan peserta didik dalam membahas soal-soal yang telah dikerjakan dan fitur redemption Question untuk memperbaiki jawaban yang salah. Quizizz dapat digunakan sesuai dengan tujuan pengguna seperti untuk melatih keterampilan membaca atau gramatika bahasa Jerman. Dengan adanya artikel ini penulis berharap media Quizizz dapat diaplikasikan menjadi media pembelajaran yang akan digunakan di berbagai mata pelajaran dan disesuaikan dengan tujuan pembelajaran. 
DAFTAR PUSTAKA

Asyar, Rayandra. 2012. Kreatif mengembangkan Media Pembelajaran. Jakarta: Gaung Persada Press Depdiknas. 2008. Panduan Pengembangan Bahan Ajar. Jakarta.

Edrová, K. 2015. Die Sprechfertigkeit Sprechen im DaF-Unterricht. Chech: Masaryk Universität.

Funk, Hermann., dkk. 2012. Studio D A1. Jakarta:Katalis

Hana, Hasanah Devi. 2019. Penerapan Media Pembelajaran Quizizz untuk Melatih Keterampilan Gramatika Mahasiswa Jurusan Sastra Jerman Universitas Negeri Malang. Skripsi. Tidak Diterbitkan. Fakultas Sastra. Universitas Negeri Malang: Malang.

Iskandarwassid, dan Dadang Sunendar. 2008. Strategi Pembelajaran Bahasa. Bandung. PT. Remaja Rosdakarya Offset.

Iskandarwassid, dan Dadang Sunendar. 2013. Strategi Pembelajaran Bahasa. Bandung:PT Remaja Rosdakarya Offset.

Kridalaksana, Harimurti. 2011. Kamus Linguistik. Jakarta:Gramedia Pustaka.

Munadi, Yudhi. 2010. Media Pembelajaran "Sebuah Pendekatan Baru". Jakarta: Gaung Persada Press.

Nurgiantoro, Burhan. 2013. Penilaian Pembelajaran Berbasis Kompetensi. Yogyakarta:BPFE

Nurrita, Teni. 2018. Pengembangan Media Pembelajaran untuk Meningkatkan Hasil Belajar Siswa. Misykat. 3(1):171.

www.sobara.wordpress.com 2012.

"Bahasa Jerman sebagai Bahasa Asing". 30 Mei. www.geothe.de/ins $/ \mathrm{id} / \mathrm{m} / \mathrm{spr} / \mathrm{wdl}$.html 2020 "untuk apa belajar bahasa Jerman". 15 Juni.

$\underline{\text { www.quizizz.com }}$ 